\title{
Medical Humanities in the English classroom: building students' professional identity through poetry
}

Humanités médicales en cours d'anglais : la poésie comme moyen d'accès à la culture de spécialité

Thibault Marthouret

\section{OpenEdition}

\section{Journals}

\section{Electronic version}

URL: http://journals.openedition.org/asp/4891

DOI: 10.4000/asp.4891

ISSN: 2108-6354

\section{Publisher}

Groupe d'étude et de recherche en anglais de spécialité

\section{Printed version}

Date of publication: 1 November 2016

Number of pages: $65-85$

ISSN: 1246-8185

\section{Electronic reference}

Thibault Marthouret, « Medical Humanities in the English classroom: building students' professional identity through poetry », ASp [Online], 70 | 2016, Online since 01 November 2017, connection on 02 November 2020. URL : http://journals.openedition.org/asp/4891 ; DOI : https://doi.org/10.4000/asp. 4891

This text was automatically generated on 2 November 2020

Tous droits réservés 


\section{Medical Humanities in the English classroom: building students' professional identity through poetry}

Humanités médicales en cours d'anglais : la poésie comme moyen d'accès à ta culture de spécialité

Thibault Marthouret

\section{Introduction: Medical Humanities and Narrative Medicine}

1 Medical Humanities and Narrative Medicine help healthcare professionals acquire a fuller understanding of patients and co-workers while supporting professional identity formation and nurturing skills of observation, analysis, and self-reflection. Close reading of poems to hone interpretative competence is a common practice in narrative medical courses and poetry-writing activities are used to foster self-awareness and empathy. In this article, we report on an experimental attempt at introducing secondyear medical students at the University of Bordeaux to the field of Medical Humanities and at raising their linguistic, phonological and cultural awareness through medicallythemed poetry during an English module. We reflect upon the use of poems and creative writing to explore and voice experiences pertaining to the students' discipline while building their language and critical thinking skills.

2 Medical Humanities have developed from the 1960s in reaction to the predominant biomedical approach to medicine, which regards the patient as a body rather than an individual. The first American Medical Humanities programmes were launched in a few universities to contest traditional views that hold medical culture as strictly scientific, technical and managerial. Today, courses have appeared in universities, both in the 
United States and abroad. More than a dozen universities in the United Kingdom such as Durham University, the University of Leicester or King's College London have incorporated the field into their curricula and most undergraduate medical programmes offer either compulsory or optional courses in at least one humanities subject (Jack 2015). Professional chairs have also been established in the field and an increasing number of master's courses are also being set up (Hurwitz \& Dakin 2009). But should this interdisciplinary area that explores the social, historical and cultural components of medicine be regarded as a disciplinary field or a set of fields? Cole et al. define them as "an inter- and multidisciplinary field that explores contexts, experiences, and critical and conceptual issues in medicine and health care, while supporting professional identity formation" (2014: 7). The field is grounded in the humanities (literature, philosophy, ethics, history and religion), social science (anthropology, cultural studies, psychology, sociology) and the arts (literature, theatre, film, visual arts). Its inclusion in the medical schools' curricula aims to help healthcare professionals acquire a better understanding of the human condition while nurturing skills of observation, analysis, empathy, and self-reflection.

3 Narrative Medicine is one of the central components of Medical Humanities. It addresses the dehumanisation at play in hospitals, where the growing role of technology in diagnosing disease, the hyperspecialisation of medical professionals and increasing caseloads, financial pressures, time constraints and paperwork have eroded empathy and promoted patient anonymity. This wholesome approach, which emerged at Columbia University in the city of New York in $2000,{ }^{1}$ focuses on the central role of narratives in the diagnostic encounter, the therapeutic process, the education of both doctors and patients, and in medical research (Charon 2001). It uses poetry, among other narrative forms, to enrich and relieve patient and caregiver experience. Over the past fifteen years, Narrative Medicine curricula and projects have proliferated throughout the world. Based on the idea that sickness unfolds in stories and that medical practice consists in understanding what these stories mean and then taking action, the act of narrative writing provides doctors with better knowledge about their patients while breaking through the technological jargon and the limitations of specialisation. Writing and sharing narratives can expand the capacity of medical professionals to reflect and act, while teaching them about aspects of medical practice not covered in textbooks and steering them away from burnout. Workshops in reflective writing, life drawing, dance, music, visual and performing arts, active discussion of works of arts, literature and film all aim to develop cultural competency, reflective practice and observational skills. They foster what Rita Charon calls "narrative competence" (2001) or the ability to actively listen to patients' stories, to understand, acknowledge and respond to the words chosen to encapsulate their disorder and gain some control over its chaos. Narrative Medicine shifts the doctorpatient relationship paradigm from detachment to "engaged concern" (Charon 2001: 1899), where diagnosis is viewed as a collaborative apprehension of meaning in which both physicians and patients are actively involved.

\section{Narrative Medicine and poetry}

In this article, we focus on poetry and its contribution to the education and training of healthcare professionals. Indeed, many Narrative Medicine workshops such as those 
led by Rafael Campo at Harvard Medical School focus on the poetic form as a way to teach medical students how to immerse themselves in patients' stories and how to tell their own narratives. Resident poet with Columbia University's Program in Narrative Medicine Rose Bromberg contends that poetry and medicine share a "special relationship":

Poetry can sharpen listening, attentiveness, observation, and analytical skills. It can refine the artistic side of medicine: Poetry allows us to express ourselves, fosters creativity, and accepts ambiguity. It enhances empathy, self-awareness, and introspection. Poetry about illness includes addressing not only the symptoms of illness, but the experience, which includes emotions and responses. [...]

The way we perceive and use poetry devices, for example: diction, tone, voice, organization/arrangement, meter/rhythm; the interactions and physical and emotional spaces/silences between the healthcare professional and patient or between the poem and reader, helps us to define and interpret ourselves and others, and to direct thoughts, feelings, and actions. Communication thus improves. Changing the cadence may influence healing and even outcomes.

The poetic voice orders thoughts and allows for control, clarity, and reflection. It

shapes our past narrative, and how we may construe our future narrative. (2008: 63)

Different parallels can be drawn between engaging with a poem and the art of diagnostic listening as they both require finely honed "interior resources-memories, associations, curiosities, creativity, interpretative powers, allusions to other stories told by this teller and others-to identify meaning" (Charon 2001: 1899). Close reading of poems to uncover their layers of signification and reach a subtler interpretation is a common practice in narrative medical courses for it makes students wary of superficial interpretations, "a clinical position that helps the clinician avoid bias, assumptions, and judgmentalness" (Shapiro et al. 2015: 3). By questioning the tone, the structure, the imagery, the perspectives of particular texts, students acquire critical thinking skills that are essential to medical professionalism. Because "narrative competence" is an integral part of phronesis or practical wisdom, failure to perform narrative tasks can impact negatively on the practice of medicine (Charon 2001). Clinical judgment is the combination of technical judgment grounded in scientific understanding, method and evidence, and humane judgment shaped by ethics, personal development and adaptability, which can all be fostered by knowledge and practice of the arts and humanities. Both components are necessary for doctors to be able to develop interpretative skills and insight (Macnaughton 2000: 24).

6 Although its role may seem less obvious than that of philosophy, medical history or even other literary genres, poetry's popularity in the field of Narrative Medicine and in the wider healthcare community is growing. Medical poetry has become a genre per se, with its literary journals and prizes such as the Hippocrates Prize for Poetry and Medicine. ${ }^{2}$ In the United States, one of the most prestigious publications for fiction, nonfiction and poetry writing about medicine and society is the Bellevue Literary Review, founded in 2000 by physician-writers who incorporate literature into their clinical teaching. However, the publication of medical poetry is not limited to literary reviews, for medical journals such as Medical Humanities, the Journal of Medical Humanities, Chest, the Journal of the American Medical Association, Families, Systems \& Health and many others include a section dedicated to the genre. These journals publish verse on all kinds of medical topics, or only poems that address their specialty. Though its content contrasts sharply with scientific studies and accounts of clinical trials, the poetry section is one of the most popular among readers (Gee 2015). The formative nature of poetry is also 
acknowledged in the British medical field. In 2014, the medical community in Scotland decided to offer all newly qualified doctors an unusual graduation gift: an anthology of poems called Tools of the Trade intended to be used to ease the young doctors through the rigours of their new profession and offer them support, inspiration and consolation (Fraser et al. 2014).

\section{The medical virtues and applications of poetry}

7 What exactly can poetry bring to the practice of medicine? Reading poetry can teach, console, amuse, move and enlighten doctors and patients alike. It can capture mundane situations they might not be conscious of as well as intense experiences. Its language relies on suggestion and association; it invites the readers to make sense of these experiences and reconstruct their meanings since it allows for individual engagement with the text and enacts complex feelings and responses to life events. Due to its allusiveness and its elliptical nature, the poetic text is often closer to actual unruly human narratives than prose. Like poems, patients' stories tend to be fragmentary, inconsistent, full of complex figurations and abrupt shifts. Reading a poem often implies apprehending a different kind of structuring than the logic in which medical students are trained. Since it appeals to both cognition and intuition, reading poetry broadens medical students' thinking. As Belinda Jack remarks, "poetry makes us understand the only half-understood; in that understanding comes relief, and it can feel very physical. This is art acting as a medicine" (Jack 2015).

Compactness is another advantage of poetry both in a medical and in an educational context, as will be discussed in section 5. Unlike textbooks or novels, reading a poem does not require long periods of time, but a particular attention to detail that makes the encounter with the text quite similar to a medical consultation in which stakes are high and time is of the essence. Racing through a poem or a consultation will result in the reader or doctor missing out on critical detail and lead to flawed interpretations of the metaphors that both poetry and medicine trade in. In the words of Danielle Ofri:

Complex biology and the many overlays of social, psychological and economic issues make medicine a complicated, and nuanced, affair. The serpentine logic often seems closer to literary metaphor than to the orderly taxonomy of knowledge that we cut our teeth on. It is our job as clinicians to work with patients to untangle these metaphors. (2013)

Grasping the workings of metaphor can help medical practitioners decipher their patients' narratives and unravel the images used to describe symptoms, which can eventually facilitate communication and increase diagnostic accuracy. Not only can becoming better acquainted with metaphor hone doctors' interpretative skills but it can also foster mental flexibility and creativity, thereby enhancing their practice of medicine. In Ofri's view, "metaphor requires the stringing together of parts of the mind that don't normally work together. Master diagnosticians [...] cogitate in the same way, actively considering ideas that don't normally sit together" (2013).

Used in medical settings, poems can give rise to new ways of interacting with patients. For instance, Danielle Ofri and Rafael Campo often distribute poems to their students, interns and patients alike, as a way to establish contact and start a conversation (Ofri 2010). In addition to putting the patients more at ease and building trust between the medical team and the patients, reading poems can help junior doctors and interns 
adopt a new perspective on certain patient profiles (Ofri 2010). Because the poetic form encapsulates aspects of the experience of illness and death that escape the realm of textbooks and scientific papers, poems can be precious teaching aids in the medical toolkit. Simple exposure to vulnerable or problematic patients leads to more negative attitudes in trainees (Shapiro 2011: 1381), which is why they need support and strategies to overcome their misgivings and prejudices. Shapiro has identified two main reasons for doctors to read medically-themed poetry: "recognition and healing", and "insight and renewal" (2010: 500). The relative lack of discussion about the "heart of doctoring" in the medical world, namely the "emotional demands of the profession triggered by overwork, stress, loss, uncertainty, suffering, and death" (2010: 500) can result in burnout, cynicism and depersonalisation. Reading medically-themed poems can help doctors overcome their isolation by identifying with the speakers and sharing the experiences related in the texts. This sense of connection can contribute to the "healing" process and can also help medical practitioners reflect on their practice and uncover new ways of improving it. Poems dealing with how patients can be dismissed or devalued in the healthcare system and how doctors can fail them on a humane level can help doctors "better understand how easily they can yield to detachment, indifference, objectification, even contempt" and in doing so it can deepen their "awareness of attitudinal and behavioural pitfalls in clinical practice" and "redirect them to alternative ways of perceiving and acting" (Shapiro 2011: 499). A poem can foster empathy and connectedness by immersing the readers in the speaker's consciousness while encouraging them to look at complex situations with a fresh eye and renewed enthusiasm.

11 The formative nature of Medical Humanities, their ability to help students and doctors reflect on the intensity of the situations they face in their daily practice prompted the author of this article to design an English for Specific Purposes (ESP) module on this very theme. Activities that appeal to students' imagination such as role-play are commonplace in language teaching classes based on the communicative approach, but the use of tasks involving freer forms of creativity not aiming at a practical production of language seems less widespread. Yet, the latter can contribute to building students' language skills in different ways while giving them the opportunity to hone their critical thinking and acquire competences that will prove invaluable in their future professional lives. For instance, creative writing can help students pay closer attention to their environment and become more active observers. It is one of the methods language teachers use to encourage students to reach beyond the purely referential aspect of English and access what John McRae calls its "representational dimension" (1996: 18). Literary texts and activities can be integrated into ESP classes but they should be introduced and studied using a different methodology than that of literature courses for, as McRae points out:

The mere understanding of what is read or heard is little more than constructing lumpen meaning out of foreign words and phrases. The development of language competence in a learner has to allow for imaginative interaction, for an element of creativity, and for an affective element of subjective, personal development, all of which go well beyond the limitations of referential language. (1996: 19) 


\section{Context and implementation of the "Exploring the Use of Medical Humanities" module at the University of Bordeaux}

\subsection{Context}

The module presented in this article is part of the English course for second-year preclinical medical students that is taught in the first semester at the University of Bordeaux. In 2015-2016, 420 students were divided into groups of twenty-five to thirty participants. The course is team-taught by the permanent and temporary teaching staff from the Département Langues et Cultures (the Language Department for the Human Sciences and Health Sciences at the University of Bordeaux). The English for secondyear medical students course comprises ten two-hour modules. Active learning represents $50 \%$ of the students' final mark and accounts for the quality and frequency of participation in class and quality of classwork and homework tasks. The other $50 \%$ is a summative assessment of language aspects seen in class (phonology, grammar, vocabulary) and of the students' reading comprehension skills. The course covers a range of subjects relating to the study and practice of medicine. The themes of the modules for the year 2015-2016 were all broadly related to the notions of patient and doctor narratives and covered topics ranging from the unhealthy scepticism surrounding vaccines to the first experience of junior doctors in the British healthcare system or ground-breaking surgeries. As regards the objectives of the English for DFGSM2 $2^{3}$ course, the different modules aimed to develop the reading, listening and speaking skills of the students in medical contexts and about medical subjects, exploring and comparing medical practice in the Anglophone world and beyond, and cultivating creativity and collaborative work through various tasks and projects (recording a podcast, making a short informative video, writing a medical poem...). The module presented here was the eighth class of the semester and it took place at the end of November 2015. As was the case with the other modules, its objectives were both cultural and linguistic. Students were introduced to the field of Medical Humanities through different texts in which particular emphasis was placed on the potentialities of medical poetry. The language work was primarily lexical and phonological.

\subsection{Phase 1: Collecting information}

The first phase of the module took place outside of the classroom. Ahead of the module, students were previously divided into four groups and each group assigned a different text to study. A worksheet divided into four sections corresponding to the four texts was handed out and students' preparatory work consisted in taking notes on different aspects of their texts. Student A read two articles by Danielle Ofri and was expected to focus on how poetry can help both doctors and patients as well as on the place of the humanities in medical school. Student B worked on an article by Niamh Kelly and completed sections of the worksheet entitled "What creativity can bring to the practice of medicine" and "How creativity in medicine can be taught and fostered". Student C read Richard Carter's presentation of the life and work of the illustrious doctor-poet William Carlos Williams in order to understand his reasons for pursuing a life of writing in addition to his career in medicine and uncover connections between creation and 
medical practice. Finally, student $\mathrm{D}$ read excerpts from a report on the evolution of patient-centred care and interdisciplinarity in American medical schools and on the wide range of activities relating to Medical Humanities offered to medical students enrolled in Cornell University's Weill Cornell Medical College. The benefits for patients and doctors of incorporating the humanities into medical education, the main principles of Narrative Medicine and the different ways in which doctors identify as artists were the main areas of Student D's preparatory work.

\subsection{Phase 2: Exchanging information on Medical Humanities}

The in-class module started with the second phase of the jigsaw reading activity as groups of four students having worked on the four different texts were formed. After twenty minutes of information exchange, the groups were invited to brainstorm and try to answer two general questions: "Do doctors really need to be creative?" and "How are the humanities and medicine related?" This activity gave rise to lively discussions within each group and a class debrief was then organised. Some students drawing inspiration from the articles they had studied and discussed highlighted how nurturing their creativity and facilitating the development of skills relating to touch and observation could help doctors find innovative solutions to the vast array of challenges facing them. Despite their young age and lack of experience, some students also emphasised the importance of critical reflection in the practice of medicine and how it can be nourished by integrating the physical, psychological and emotional self into the healthcare system. Other students, however, remained unconvinced and voiced their fears that devoting any time to the study of the humanities would automatically impact negatively the training of junior doctors by depriving them of the opportunity to acquire more science-based knowledge.

\subsection{Phase 3: Identifying voices, tones and experiences in medically- themed poems}

Following the initial thirty-minute phase, the introduction to Alastair Gee's "Ode on a Stethoscope" was handed out to students. In this article, Gee gives an overview of the expanding publishing landscape of medically-themed poetry in peer-reviewed medical journals in the United States. In the first part of his article, Gee quotes several extracts from poems written by health-care workers and doctors. Once students had read the introduction, they were asked to turn their document over and look at the screen on which the poetic extracts incorporated into Gee's article were projected. Students had to remember what experience was conveyed in verse. The poems in question were physician Adam Possner's "Drug Holiday" in which an addict addresses a pill and begs it to remain in its bottle, Vanderbilt University anaesthesiologist Doug Hester's "An Intern's Recollection of a Night at the V.A., July 2004", oncologist Amir Steinberg's vivid evocation of a devastating multisystemic syndrome called POEMS (Polyneuropathy, Organomegaly, Endocrinopathy, Monoclonal Gammopathy, and Skin changes), pathology professor Sanjeev Narang's "Ulcerative Colitis" and an excerpt from Persian philosopher Avicenna's Canon of Medicine.

16 This reading comprehension phase followed by the poetic quiz exposed students to creative uses of medical English and, more specifically, to the great diversity of topics 
that characterises medical poetry while prompting them to identify the different voices and tones employed in the poetic excerpts. Discussion of some linguistic features of the extracts quoted in Alastair Gee's article happened rather organically since constructing the meaning of a poem is a conscious process that requires some awareness of its formal features. Form is inseparable from content in any poem. Thus, reading poems can encourage learners to extend their repertoire of linguistic structures through the close reading and meaning construction process that it entails. Hanauer posits that the comprehension difficulties a learner will encounter can bolster acquisition of the target language since learners are forced to assess their current linguistic levels. Grounding his thought in Widdowson's work, Hanauer highlights the de-familiarisation of language at work in poetry and its capacity to lead the reader to find new ways of understanding the structures used in the text, which results in a "widening of the options of usage for the structures that were noticed and negotiated in the meaning construction process" (2001: 298). Hanauer suggests that reading poems in a second language improves the language learning process by directing "the reader to focus on form and thus has the potential of raising the reader's ability to notice input and notice the gap between input and output" (2001: 299).

\subsection{Phase 4: Raising students' phonological and cultural awareness through poetry}

The objective of the next phase of the module was once again to direct students' attention to the poetic form and its potential use in medically-themed poetry but this time from a more phonological standpoint. Indeed, in a poem, feeling and meaning rely heavily on sound patterns. Rhyme and/or sound combinations such as assonance, consonance, and other patterns of phoneme repetition convey thoughts and feelings and intensify connotations. A slide comprising thirty-two words was projected and pairs of students were asked to match them according to their pronunciation. The words could be paired by their rhyme (medicine/sin; language/pilgrimage; plain/pain; stare/care) or consonance (diaphragm/from; limp/lump) and all were taken from two poems by general internist and acclaimed poet Rafael Campo: "What the Body Told", which explores what the human body reveals through a doctor-speaker's attempts at deciphering its signs and "The Abdominal Exam", whose accumulation of medical terminology contrasts sharply with the powerlessness experienced by the doctorspeaker who is examining a dying patient. As students matched the words, they expanded their phonological awareness by focusing on the pronunciation of mostly medical terms such as diaphragm, nodes, pain, care, lump, etc. Then, incomplete versions of Campo's two poems were handed out to the students. There were fifteen gaps in the poems, which students were asked to fill with the words they had just played with. In order to complete this task, they had to consider both the semantic and the phonological contexts in the different stanzas. Repetitions, parallelisms, reiterations of syntactic structures helped the students decide which poems and which lines within said poems the words belonged to. Students responded to this activity on sound and rhyme enthusiastically. They were then encouraged to discuss in small groups what they perceived to be the meanings and feelings conveyed in the two poems and most of them used the phonological devices they had identified to build their interpretations by highlighting their functional roles. They shared and compared their interpretations and, in pairs, read the poem they preferred to their partner. Prior to 
the oralisation of the poems, students were invited to practise and pay attention to both sentence and word stress.

Polysemy is a crucial feature of poetry and one that makes it precious to language teachers for they can use it to generate student-centred activities and small group discussions in which the ESP learners are actively engaged. Using medically-themed poetry in the "Medical Humanities" module helped train students in the process of multiple readings of the same text. It encouraged them to come up with their own interpretations of Campo's poems, an activity which simultaneously sustains their involvement and reinforces their critical thinking skills. Students were inspired by the themes of the poems studied but also by the knowledge that there was no definitive take on the poems, that their renditions were as valid as their classmates' as long as they could produce linguistic evidence to support them. The DFGSM2 medical students blended their own knowledge and experience of medical practice with information from the texts to create a wider and more comprehensive understanding of Rafael Campo's poems and in doing so, it is likely that they increased their own cultural and medical awareness. Indeed, while studying the different textual meaning elaboration strategies implemented by dyads of students reading poetry in a foreign language, Hanauer discovered that an expanded world knowledge was one of the positive student outcomes:

Poets can and do subvert common cultural beliefs, play with cultural meanings and construct personal symbolic codes. However, in doing so they also activate the cultural context within which they are functioning (Widdowson 1975). The process of questioning, negotiating, proposing interpretations, and using world knowledge which are part of the process of understanding a poem involve activating any world knowledge the language learner has in relation to the cultural context of the poem. This process can direct the reader to view the distance between the poem's content and her/his own knowledge of the target culture. It is in this way that the poetry reading task can enhance cultural awareness. (2001: 319)

In the case of medically-themed poetry, the cultural context is that of a community of discourse and practice to which the students aspire to belong. Poems can give students new perspectives on said discourse and practice especially when they are written by patients or other actors of the healthcare system working in settings French medical students are not familiar with. Medical Humanities aim to enhance doctor-patient communication by allowing practitioners to appreciate their patients' narratives and incorporating them into their treatment. By raising medical students' cultural awareness, reading poetry can guide them towards these objectives and simultaneously develop their phonological, syntactical and lexical skills, which makes it a precious tool for ESP teaching.

\section{The final task}

\subsection{Rationale and learning outcomes}

Having read extracts of medically-themed poems by various authors and two poems by Rafael Campo, the DFGSM2 students were invited to write a medical poem either in prose or verse. To increase their motivation, they were given the option to enter a DFGSM2 poetry competition. Submissions were uploaded to the Moodle learning platform and students from another group voted for their favourite entry. They were 
free to adopt the style, form and genre of their choosing and could use words from a toolbox as inspiration or come up with their own vocabulary. This poetry-writing task was initiated in class so that students could receive the help of their fellow classmates and their teacher with the writing of their text. However, due to time constraints, few poems had been entirely composed by the end of the module. The students who wanted to take part in the DFGSM2 poetry competition were given one week to submit their poems.

21 The rationale behind the choice of the final task was twofold. From a language teaching point of view, adopting a "hands-on" approach to poetry by getting students to write a poem was a way to show them that they possessed the resources to produce a poetic text in a second language and to give them access to the potentialities of poetry as a language resource. In the context of the ten-week English course, this activity came as a refreshing change to the usual pedagogical modes of practice. It also allowed students to exploit their knowledge of the conventions of the poetic discourse of their mother tongue as well as those of songs, lyrics and poems in the target language, and reflect on their experiences, fears and ambitions as future doctors. They combined the characteristics of the poetic forms they knew and played with their resources in the target language, testing its limits and elasticity, which, according to Maley and Duff, is one of the fundamental conditions for learning in a foreign language:

All poets stretch the language in this way: by coining new words, creating new collocations, experimenting with sound, using old words in new ways, and so on. [...] Through interactive writing tasks [learners] can also reach out for the limits of the possible themselves. In one sense, the writing of poetry is an ideal task for language learners because of its tolerance of "error"[...]. This is the sand-pit where guiltless children (and adults too) can try out their constructions. [...] The student is transformed from a spectator into a participant. (1989: 9)

Experimenting with the sounds provided in the toolbox allowed the less proficient students to engage with the task while reinforcing their sensitivity towards the rhythmic and phonological aspects of English. Playing with the poetic form and its components like repetition, word stress, alliteration and rhyming patterns was a way for many students to progressively focus on the meaning they wanted to infuse their texts with. The welcome support of rhymes such as "prescription/radiation", "neural/ hospital", "treat/defeat" helped get them started on writing their poems while more advanced students often began by choosing the theme they wanted to address before looking for notions, structures and vocabulary.

The compactness of the poetic form led students to establish links between different experiences and to connect thoughts with feelings while addressing complex issues and sensitive topics such as death and disease. To create the "self-contained world" of the poem (Maley \& Duff 1989: 12), students often expressed themselves with concision, they used metaphor as a device to economically encapsulate meaning as well as language functions such as connotation, denotation, symbolism, and imagery to condense, convince, move or evoke, thereby practicing modes of communication which will be useful to them in their future careers as doctors. In the words of Janette Hughes, "poetry encourages an economy and precision in language that transfers to other types of oral and written communication" (2007: 1). Composing a poem can also help students see the complexities of their environment and life experiences in a new light. According to Hughes, 
Poetry is [...] a way of knowing. Poetry both requires and facilitates a concentration of mind or sustained attention to which our hectic lives have unaccustomed us. The linking of the strange with the familiar through the image or even through wellplaced line breaks is perhaps what makes poetry so powerful. Poetry transforms the way we see the commonplace through new perspectives. (2007: 1)

Poetry writing can serve as a tool to improve learners' observation skills and enrich their experience and their understanding of the world around them as it forces them to question what was thus far considered obvious, unavoidable or alien. It promotes critical thinking skills by strengthening reflection on medical practice and representations. It also develops self-awareness and encourages health practitioners to adopt patients' perspectives (Charon 2001: 1901). In countries where Medical Humanities programmes have become a common offering at medical school, there has been a growing interest among medical educators in the students' original writing, including poetry. Many journals published by medical schools such as Body Electric (Chicago College of Medicine, University of Illinois) feature essays and poems composed by students and medical school literary contests such as The William Carlos Williams Poetry Competition, sponsored by the Department of Family and Community Medicine at Northeast Ohio Medical University, recognise and promote student poetry. This interest has been complemented by the development of research into the benefits of poetry writing for medical practitioners and students. ${ }^{4}$ By writing about their experiences, medical students get to re-live them from a different perspective. The use of different voices in a poem helps them to investigate other people's take on the medical event, be they patients, family members or colleagues. Training in point-ofview writing, which teaches students how to write from the patient's perspective about his or her illness and situation, has been shown to effectively increase students' ability to "adopt another's point of view, develop empathy for another, express emotion, including negative emotion, demonstrate insight, question an achievement-oriented approach to patient care, and consider spiritual aspects of serious illness" (Shapiro et al. 2006: 104). In addition to the skills medical students can acquire through creative writing, interest in their productions has been sparked by the realisation that "poems are a method by which medical students can make emotional sense of their relational experiences in medical school" (Shapiro \& Stein 2005: 286). Besides exploring the patient-doctor relationship, poetry has been shown to offer students a space outside what Jerome Bruner termed the "logico-scientific" or "paradigmatic" discourse (1986) where they can question conventional professional and organisational behaviours, which eventually allows them to investigate their role within their community of practice. Therefore, student productions can provide feedback for medical educators, shedding greater light on the challenges students face and the learning processes through which they grow as doctors.

\subsection{Overview of the DFGSM2 students' productions}

Here, the poems analysed are those written by the two groups of students I taught, since they all participated in the module and were prepared for the final task in a similar way. Though some students were initially uneasy with the nature of this activity and had misgivings towards poetry, they soon overcame this once they started playing with words and sounds. Many of them used poetic structure as a form of scaffolding to complete this activity. Far from being an obstacle and a source of 
apprehension, the phonological and prosodic dimensions of poetry helped them make headway. Despite being told their poems did not need to be written in verse or follow any predetermined rhyming or rhythmic patterns, all the medical students who took part in this activity chose to use lines and rhymes. The scaffolding they found in the poetic form had greater appeal than the absolute freedom afforded by the open form of free verse. When I designed the "Medical Humanities" module, I was aware that students would not have enough time to finish their poems in class. The objective of this final stage was to prepare the students for the final task and have them take their first steps towards it. The decision to enter the DFGSM2 Poetry Competition was left entirely up to them. I made it very clear that the poems would not be graded. I was pleasantly surprised when out of the forty-six medical students and four midwifery students I taught, forty-seven sent me poems whose length ranged from three lines to eight four-line stanzas.

Table 1 presents the different categories of poetic voices used by my students to deal with the themes that occupied their minds. In order to obtain a clearer representation of the topics addressed by the students in their poems, a thematic breakdown of their productions is shown in Table 2. Each poem was categorised only once according to its predominant emphasis. Besides the substantial range of speakers and themes, the student poems were characterised by their tonal variety. Some opted for a lighthearted, witty tone ("Of all the things that can be lost/Your mind is what you'll miss the most.") while others gave their poems a more angst-ridden quality ("I am going to take away from him/The last thing he possesses, /Hope"). Some poems were playful pastiches of existing texts such as "The Night's Doctors' Oath" after Games of Thrones "Oath of the Night's Watch": "I pledge my life and honor to the hospital,/For this night and all the nights to come." One student even gave voice to an endoscope: "A mission had been given to me:/Finding something suspect and ugly,/And according to the instructions,/ It was located in the right corner of the colon." However, the three main thematic categories revolved around their fears, their representations of their future profession and patients.

Table 1: Categories of Poetic Voice in the DFGSM2 Students' Poetry

\begin{tabular}{|l|l|}
\hline Type of voice & Number of poems \\
\hline Medical student & 13 \\
\hline Doctor & 10 \\
\hline Patient & 7 \\
\hline Midwife & 1 \\
\hline Personified piece of medical equipment & 1 \\
\hline Personified disease & 1 \\
\hline Non-specific voice & 14 \\
\hline
\end{tabular}


Table 2: Thematic Summary of DFGSM2 Student Poetry

\begin{tabular}{|l|l|}
\hline Theme & Number of poems \\
\hline The fears of medical students & 10 \\
\hline Idealistic vision of the medical profession & 8 \\
\hline General representation of the medical world & 7 \\
\hline Patients & 7 \\
\hline The life and characteristics of medical students & 5 \\
\hline The effects of drugs and treatments & 3 \\
\hline Diseases and their mechanisms & 2 \\
\hline The human body & 2 \\
\hline Other - Non medically-themed poems & 3 \\
\hline
\end{tabular}

The fears addressed in the students' poems are both related to the present time and to the challenges they will have to face in their careers. Rites of passage such as attending their first autopsy and other landmarks in the students' medical training are common themes in poems which convey the emotional impact of these experiences: "Trying not to look at the victim's face,/His eyes forever staring into space,/We watched as the doctor handled the knife/ Searching to find what ended his life." The pressure of exams and of the vast quantity of scientific knowledge students have to acquire is often counterbalanced by a feeling of relative inadequacy and incompetence ("Even though I'm always buried in my books,/A coronary heart disease I cannot diagnose") and the concern that studying hard will not prepare them for the reality of their first day as a doctor: "Pills, shots, creams and cures,/I was up to learn more and more/I got rid of my 2nd medical contest,/I just didn't care about the rest/But once my first day as a junior doctor started,/I realized I didn't have that much information in my head." In other poems, this fear logically extends to the management of patients and many speakers are concerned with failing them, either by making a medical error ("Suddenly I botched his IV/And he died there because of me.") or by not being able to become a "real doctor" and reach the state of complete detachment and the purely biomedical approach they sometimes associate with medical professionalism: "I want to be a good doctor/ To avoid making errors./As a med student I have to see a body/As a body, not as a human, as a pathology." However, alternative representations of the doctorpatient relationship are conveyed in the poems: "Good diagnoses are part of Medicine,/ But Medicine also includes humanity,/With appropriate empathy,/ Helping patients to cope with their diseases." Highlighting the vast theoretical and scientific knowledge required by medical training and contrasting it with the humanity of the patients seems to be as common a trope in French students' poetry as it is on the other side of the Atlantic. Indeed, Poirier, Ahrens and Brauner analysed poems by medical students published in Body Electric and noted that "championing the humanity of the patient and chafing at the abstractness of the basic sciences are hallmarks of the beginning medical 
student" (1998: 474). Feeling powerless in front of their future patients' suffering, the fear of losing them or of meeting a patient who begs them to be euthanised are also the foci of several poems. Voicing their concerns in a creative endeavour may help students transcend them or at least put them in perspective. Writing allows medical students to

deal with their experiences in a different way: not only do they seek exact words and images to represent an emotional experience but they also share these personal moments with others and thus learn that they are not alone in their questioning. (Poirier et al. 1998: 477)

Through the writing process, students also paint a picture of the values, standards and expectations of the educational system to which they belong, thus providing valuable feedback and "insights into how [they] view and resolve the professional relationship systems in which they are embedded" (Shapiro \& Stein 2005: 285). When depicting future professional situations and the role of doctors, some students used a playful tone to paint an idealised, albeit tongue-in-cheek, portrait. Medicine is described in several texts as a "noble art" and doctors are heroes who "guide" patients, "give them wings", and fight "epic battles" against diseases. Some laudatory poems are more specific when students express their admiration for a particular registrar or consultant, or when they depict their favourite specialties and the skills they require: "An outstanding show of ability,/ The smallest mistake brings calamity./Joining self-control and bold accuracy/ There is no nobler art than Neurosurgery." Beneath the eulogistic and exalted tone of some of the poems, a genuine belief in the importance of medical practitioners' role from both a social and personal standpoint can be perceived. "Fighting against death" is presented as a calling that requires total dedication: "it's not just a profession,/it's a vocation." One student described his motivation and drive to become a doctor through the image of "the little voice/Inside him, inside his heart,/that leads him to this noble art."

"Patients" and "general representations of the medical world" are the third most commonly addressed poetic themes by my students, topics reflecting their overall lack of experience. Indeed, in France the first year of medical school is entirely dedicated to taking the medical school entry exam and at the time when this module was dispensed, students had little to no clinical experience. Consequently, the relationship between caregiver and patient is not explored in detail and when it is featured in the poems, it is simplified and reduced to a dominant emotion (fear of hurting patients on the medical students' part, extreme gratitude on the patients'). Only two poems spoke of actual interaction between a patient and members of the medical team. In the first one, a haiku, nurses are laughing at an elderly patient's jokes. The point of view is that of an outsider looking in. In the other poem, the speaker is about to deliver a terminal prognosis to a cancer patient. No words are spoken but the patient's resigned body language is described throughout the poem: "The chemotherapies took his hair./ Tobacco took his lungs./I try to smile./He fixedly looks at me./He knows the reason for the appointment." This poem is the only one out of the forty-seven written by my students that centres around the communication between a patient and a doctor. When portraying patients in a more in-depth manner, the students preferred to remove themselves from the situation and gave voice to the patients using first-person speakers. By resorting to this point-of-view writing device, they managed to empathise with their subjects and describe dire situations such as the despair of a young patient placed in protective isolation or the suffering of patients battling addiction or cancer. 
Even though most poems portraying patients are imbued with pathos and convey their thoughts and feelings in these life-threatening circumstances, one student chose to focus on an organ transplant patient's relationship with his new hand, thus investigating another side of patient experience: "And that from that second on,/We shared the strongest of bonds."

\section{Concluding remarks}

\subsection{Raising awareness of the intersection between medicine and poetry by developing students' “reactional” language}

Despite some lukewarm reactions during the brainstorming activity of the "Medical Humanities" module on the links between medicine, creativity and the humanities, the response of students to the poetry writing task was enthusiastic. Reading medicallythemed poems seems to have opened them up to the possibilities of the genre and adopting a "hands-on" approach to these texts by playing with sounds and rhythms eased them into the final task. Upon studying their poems, it would seem their positive response was also due to the opportunity they were given to use aspects of English they learnt from songs, TV series and popular culture, and blend them with the scientific and medical English acquired through the first seven modules of their medical English course. Writing a poem also enabled them to use their own knowledge of the medical world and its practices, and infuse it with their own culture and personality. By addressing themes such as professional identity, medicine as a calling, the limits of medicine, the dehumanisation process at work in the healthcare system, and by identifying with patients, these students displayed signs of the type of creativity which, according to Niamh Kelly, doctors should be encouraged to develop in order to hone their problem-solving skills and improve their communication with their co-workers and their patients:

Sharing one's creative output with others encourages connection and relationship building and can allow a health care provider to connect with colleagues and individual patients in a spirit of shared understanding and appreciation. [...] We could achieve widespread nurturing of creativity by encouraging talk of our creative endeavors to infiltrate [...] the small talk that takes place in health care teams as they move between procedures or patients, the corridor talk, the proverbial "water cooler" conversations that touch on our lives outside of the task at hand. (2012: 1476)

31 From a linguistic point of view, by mobilising creative language skills, the medical students appropriated sounds and rhythm, played with syntactic structures, made technical terms and new vocabulary their own, and connected with English in a way that was personally relevant and meaningful to them, thereby partaking in one of the cultural practices of their professional community. Brown and Yule divide the functions of language into two main categories: "transactional language" and "interactional language". The former's objective is "the efficient transference of information" (1983: 2); it is used to give instructions or directions and its nature is primarily utilitarian. It is this type of language that students are predominantly taught in the other modules of the medical English course when, for instance, they are invited to explain a procedure or a protocol to their fellow classmates. Speakers use "interactional language" in the situations mentioned by Kelly in the above quotation to 
"maintain social relationships, [...] negotiate role-relationships, peer-solidarity, the exchange of turns in a conversation" (1983: 3). This interpersonal language is mobilised during phases of group discussion or pair work, but it is not the main object of study of the "Medical Humanities" module.

As Maley and Duff point out, poetry represents a third category of language they call "reactional" and whose purpose is to make people "react personally to other people's ways of seeing things" (1989: 10), something poetry can do very economically. This development of a personalised reaction to texts, which engages not only the intellect but also the feelings, is a very important part of the language learning process (1989: 10). Advocates of Medical Humanities and Narrative Medicine also consider this type of language to be essential to the development of sound doctor-patient relationships and accurate diagnostic skills. The "Medical Humanities" module aimed to raise awareness of this intersection between medicine and poetry, and to give students the opportunity to tap into their creativity and practice their "reactional" language skills. When they realised in class that they were able to produce a type of discourse which is often regarded as complex or even impenetrable, their confidence in their language skills increased and most of them were spurred on to pursue the task beyond the classroom. Poetry can be gratifying and motivating for ESP students and it is a useful tool for both teachers and doctors to have in their kit.

\subsection{Pedagogical issues}

33 The experimental nature of this attempt at using poetry in the medical English classroom has revealed that some key aspects of the module should be changed and improved in order to maximise its learning outcomes in the future. First of all, introducing the students to the field of Medical Humanities and having them read medically-themed poems in view of writing their own text in a two-hour module was very ambitious. It may have been more profitable for students to have more time in class to write their poems and receive help and feedback. The poems that were submitted by the students were read, annotated and some grammatical or lexical suggestions were made but too little time was dedicated to this important stage the following week since every module had a different theme and set of activities to be completed before the final exam.

Talking with the students about their different choices and helping them with the editing process would certainly have contributed to maximising the learning outcomes of the module. Not allowing students enough time to read their texts out loud and make the best possible use of the advantages of the poetic form in terms of speech patterns, rhyme and intonation, also seems like a wasted opportunity. Inviting them to record an oral reading of their poems linked with their print version or to create a digital poem would have appealed to the multimodal nature of poetry and students' multiple literacies (Hughes: 2014).

Another strategy that could have been deployed to maximise the potentialities of poetry as a teaching resource would have been to ask students to discuss their poems in small groups, which would have provided a linguistically rich activity and would have reinforced the empathetic and interpretative qualities of the task. Equally, getting them to collaborate on a poem could have fostered communication and empathy and it would have prompted them to describe and compare their experiences as medical 
students. Finally, even though the second-year students were able to voice their hopes and fears as well as their vision of medicine and of their future profession, the purely theoretical nature of their medical knowledge prevented them from accessing all the potentialities of poetry as a way to reflect on professional relationships and practices.

Future research should focus on how more advanced medical students such as fourthor fifth-year students with actual clinical experience can use poetry in English to convey the evolutions in the representations of their identity as doctors, of their social and professional roles, of their interactions with patients, and of their strengths and shortcomings both as individuals and as medical practitioners. The productions of these more experienced students could also be studied to learn more about the specificities of medically-themed poetry and the role of poetry itself in the foreign language acquisition process.

BROMBERG, Rose. 2008. "Poetry and medicine". The Medscape Journal of Medicine 10/3, 63.

BRown, Gillian \& George YULE. 1983. Discourse Analysis. Cambridge: Cambridge University Press.

BRUNER, Jerome. 1986. Actual Minds, Possible Worlds. Cambridge: Harvard University Press.

CARTER, Richard. 1999. "William Carlos Williams (1883-1963): Physician-Writer and 'Godfather of Avant Garde Poetry”'. The Annals of Thoracic Surgery 67/5, 1512-1517.

CARTER, Ronald. 1988. "Directions in the teaching and study of English stylistics", in SHORT, M.

(ed.), Reading, Analysing and Teaching Literature, 10-21.

CHARON, Rita. 2001. "Narrative Medicine, a model for empathy, reflection, profession, and trust". Journal of the American Medical Association 286/15, 1897-1902.

COLE, Thomas R., Nathan S. CARLIN \& Ronald A. CARSON. 2014. Medical Humanities: An Introduction. Cambridge: Cambridge University Press.

FRASER, Lilias, John GILIES, Kate HENDRY, Lesley MORRISON \& Revd A. NEWELL (eds.). 2014. Tools of the Trade: Poems for new doctors. Edinburgh: Scottish Poetry Library.

GEE, Alastair. 2015. "Ode on a Stethoscope". The New Yorker, retrieved from <http://

www.newyorker.com/tech/elements/ode-stethoscope> on 14 January 2015.

HANAUER, David Ian. 2001. "The task of poetry reading and second language teaching”. Applied Linguistics 22/3, 295-323.

HUGHES, Janette. 2007. "Poetry: A powerful medium for literacy and technology development". What Works? Research into Practice Series, retrieved from <http://www.edu.gov.on.ca/eng/ literacynumeracy/inspire/research/Hughes.pdf> on 15 January 2016.

HUGHES, Janette. 2014. "Case study IX: Digital literacy”. In DYMOKE, S., M. BARRS, A. LAMBIRTH \& A. WILsoN, Making Poetry Happen: Transforming the Poetry Classroom. London: Bloomsbury, 191-202.

HURWITZ, Brian, \& Paul DAKIN. 2009. "Welcome Developments in UK Medical Humanities". Journal of the Royal Society of Medicine 102/3, 84-85.

JACK, Belinda. 2015. "The rise of the medical humanities". Times Higher Education, retrieved from <https://www.timeshighereducation.com/features/the-rise-of-the-medical-humanities/ 2018007.article> on 22 January 2015.

KELLY, Niamh. 2012. “What are you doing creatively these days?". Academic Medicine 87/11, 1476.

MACNAUGHTON, Jane. 2000. "The humanities in medical education: context, outcomes and structures”. Medical Humanities 26/1, 23-30. 
MALEY, Alan \& Alan DUFF. 1989. The Inward Ear: Poetry in the Language Classroom. Cambridge: Cambridge University Press.

MCRAE, John. 1996. "Representational language learning: from language awareness to text awareness”. In CARTER, R. \& J. MCRAE, Language, Literature and the Learner. London: Longman, 16-40.

OFRI, Danielle. 2010. "Poetry in medicine”. Psychology Today, retrieved from <https:// www.psychologytoday.com/blog/medicine-in-translation/201002/poetry-in-medicine> on 12 February 2010.

OFRI, Danielle. 2013. "How creative Is your doctor?". The New York Times, retrieved from <http:// well.blogs.nytimes.com/2013/03/14/how-creative-is-your-doctor/?smid=pl-share> on 14 March 2013.

POIRIER, Suzanne, William AHRENS \& Daniel BRAUNER. 1998. "Songs of innocence and experience: student's poems about their medical education”. Academic Medicine 73/5, 473-478.

SHAPIRO, Johana. 2010. "Take 2 poems and call me in the morning: Reading medically themed poetry for insight and renewal”. The Journal of Clinical Outcomes Management 17/11, 499-504.

SHAPIRO, Johana. 2011. "The least of these: Reading poetry to encourage reflection on the care of vulnerable patients”. Journal of General Internal Medicine 26/11, 1381-1382.

SHAPIRO, Johana \& Howard STEIN. 2005. "Poetic license: Writing poetry as a way for medical students to examine their professional relational systems". Families, Systems, \& Health $23 / 3$, 278292.

SHAPIRO, Johana, L. RUCKER, J. BOKER \& D. LIE. 2006. "Point-of-view writing: A method for increasing medical students' empathy, identification and expression of emotion, and insight". Education for Health 19/1, 96-105.

SHAPIRO, Johana, L. L. NIXON, S. E. WEAR \& D.J. DOUKAS. 2015. "Medical professionalism: what the study of literature can contribute to the conversation". Philosophy, Ethics and Humanities in Medicine 10/10, 1-8.

\section{NOTES}

1. The field of Narrative Medicine was conceptualised by an interdisciplinary group of faculty from the College of Physicians and Surgeons and the School of Arts \& Sciences of Columbia led by Dr. Rita Charon in 2000.

2. The Hippocrates Society for Poetry and Medicine has awarded its annual Hippocrates Prize for Poetry and Medicine in three categories (the international open category, the international Young Poets award, and the UK NHS category) since 2009.

3. Diplôme de Formation Générale en Sciences Médicales $2^{e}$ année or second year of Medical School

4. Studies on medical students' poetry have shown that creative writing helps students voice and sustain their idealism (Poirier et al. 1998). 


\section{ABSTRACTS}

Medical Humanities and Narrative Medicine help healthcare professionals acquire a fuller understanding of patients and co-workers while supporting professional identity formation and nurturing skills of observation, analysis, and self-reflection. Close reading of poems to hone interpretative competence is a common practice in narrative medical courses and poetry-writing activities are used to foster self-awareness and empathy. Here, we report on an experimental attempt at introducing second-year medical students at the University of Bordeaux to the field of Medical Humanities and at raising their linguistic, phonological and cultural awareness through medically-themed poetry during an English module. We reflect upon the use of poems and creative writing to explore and voice experiences pertaining to the students' discipline while building their language and critical thinking skills. Despite their initial misgivings, the students produced medically-themed poems addressing topics such as medicine as a calling or the realities of their situation as medical students. However, their lack of clinical experience prevented them from accessing all the potentialities of poetry as a way to reflect on professional relationships and practice.

Les Humanités médicales et la médecine narrative permettent aux professionnels de santé d'acquérir une meilleure compréhension de leurs patients et de leurs collaborateurs tout en étayant le développement de leur identité professionnelle et en cultivant chez eux les compétences relatives à l'observation, à l'analyse et à l'autoréflexion. La lecture détaillée de poèmes afin d'affiner les capacités d'interprétation est une pratique courante dans les cours de médecine narrative, tout comme le recours aux activités d'écriture poétique pour promouvoir la créativité, la connaissance de soi et l'empathie. Cet article présente un module expérimental d'anglais ayant pour but d'initier des étudiants de médecine à l'Université de Bordeaux au champ des Humanités médicales et de les sensibiliser à leur culture de spécialité ainsi qu'aux réalités phonologiques et prosodiques par l'intermédiaire de poèmes traitant de sujets médicaux. Il propose une réflexion sur la place de la poésie dans le cours d'anglais médical et le recours à l'écriture créative comme outil permettant aux étudiants d'explorer et de rapporter certaines expériences de leur champ disciplinaire ainsi que de consolider leurs compétences langagières.

\section{INDEX}

Mots-clés: écriture créative, humanités médicales, médecine narrative, poésie, pratique réflexive

Keywords: creative writing, medical humanities, narrative medicine, poetry, reflective practice

\section{AUTHOR}

\section{THIBAULT MARTHOURET}

Thibault Marthouret teaches English for Specific Purposes at the University of Bordeaux. He specialises in English for Health Sciences, Life Sciences and Educational Sciences both at an undergraduate and postgraduate level. He holds a master's degree in English studies and wrote his dissertation on Sylvia Plath's poetry. His own poetic work has appeared in many journals and his first collection, En perte impure, was published in 2013. thibault.marthouret@u-bordeaux.fr 